\title{
Spatiotemporal Diurnal Modulation Characteristic of Wind Speed and Power Generation Revealed by Its Actual Measurement Data Information Processing
}

Jie Wan

Harbin Institute of Technology

Shuangshuang Fan

Harbin Institute of Technology

Kun Yao ( 19b353009@stu.hit.edu.cn)

Harbin Institute of Technology Shenzhen https://orcid.org/0000-0002-6136-7741

Ke Han

Harbin University of Commerce

Peng E

Harbin Institute of Technology

Jilai Yu

Harbin Institute of Technology

\section{Research Article}

Keywords: Terrestrial atmosphere turbulence, Temporal-spatial characteristics, Diurnal modulation, Wind speed, Wind power generation, Uncertainty

Posted Date: December 6th, 2021

DOI: https://doi.org/10.21203/rs.3.rs-1051667/v1

License: (9) This work is licensed under a Creative Commons Attribution 4.0 International License.

Read Full License 


\title{
Spatiotemporal Diurnal Modulation Characteristic of Wind Speed and Power Generation revealed by its Actual Measurement Data Information Processing
}

\author{
Jie Wan ${ }^{1,2}$, Shuangshuang Fan $^{1}$, Kun Yao ${ }^{3 *}, K^{*} \mathrm{Han}^{4+}$, Peng $\mathrm{E}^{1,2}$, Jilai $\mathrm{Yu}^{2}$ \\ ${ }_{2}^{1}$ Laboratory for Space Environment and Physical Sciences, Harbin Institute of Technology, Harbin 150001, China \\ ${ }_{3}^{2}$ School of Electrical Engineering \&Automation, Harbin Institute of Technology, Harbin, 150001, China \\ ${ }^{3}$ School of Mechanical Engineering and Automation, Harbin Institute of Technology, Shenzhen, 518055, China \\ ${ }^{4}$ School of Computer and Information Engineering, Harbin University of Commerce, Harbin, 150028, China, \\ *Corresponding author (E-mail: 19b353009@ stu.hit.edu.cn); + Corresponding author (Email: hanke@ hrbcu.edu.cn)
}

\begin{abstract}
Atmospheric turbulence is an intrinsic factor that causes uncertainty of wind speed and its power generation by wind turbine. The research of atmospheric turbulence characteristics of wind farms can be used to reduce this uncertainty. In this paper, enough measurement data getting from actual wind farms is used for information processing to quantitatively analyze the daily variation of wind speed and its power output characteristics. Furthermore, the concept of spatiotemporal diurnal modulation characteristics of atmospheric turbulence is proposed with a global scope, which is an intrinsic property of wind. Besides the daily weather processes, the average hourly wind speed has a short-term modulation effect on its turbulence and provides a modulation characteristic on wind speed uncertainty. Moreover, the long-term modulation process is affected by seasonal and regional factors, indicating that it has spatiotemporal characteristics. This atmospheric turbulence characteristic has similar effects on characteristic description parameters. However, the characteristics description parameters of wind speed and wind power variation fail to reflect such intrinsic characteristics that are not affected by the spatiotemporal diurnal modulation characteristics of atmospheric turbulence. This indicates that they do not have diurnal characteristics. Finally, the application of spatiotemporal diurnal modulation characteristics on the evaluation of frequency control in power systems is discussed. The results show that this method can effectively improve the power generation quality of large-scale wind power.
\end{abstract}

Keywords: Terrestrial atmosphere turbulence; Temporal-spatial characteristics; Diurnal modulation; Wind speed; Wind power generation; Uncertainty

\section{Introduction}

As one of the renewable resources, wind energy is being used worldwide[1, 2, 3, 4]. Researchers from various countries have carried out lots of work on the current status and future of wind power in their countries[5, 6]. Development of wind power from the viewpoints of Political, social and technical issues was analyzed in [7]. In China, wind power is the leading energy development sector under the low-carbon development policy, while a series of wind power development plans were drawn up by government $[8,9,10]$.

However, the uncertainty in wind speed poses challenges for the utilization of wind power $[11,12,13]$. In addition to randomness and volatility, intermittency is another problem that plagues the large-scale application of wind energy [14]. A series of strategies and paths have been studied and explored to use large-scale wind power safely and efficiently[15]. China's feed-in tariff mechanism for largescale wind power is shown in [16]. Moreover, the characteristics of Chinese energy structure determine the developmental path of rapid and deep peak regulation of thermal power $[17,18]$. Several novel methods were proposed for wind power to smooth the output power of wind energy [19, 20].

Considering the uncertainty of wind energy on grid connection, research work focuses on wind power prediction [21, 22], including data model, physical model, and hybrid model [23, 24, 25]. The continuous development of artificial intelligence algorithms has further expanded the scope of its application to new areas[26, 27]. Using data obtained from data-rich farm, high-dimensional data features are obtained through a series of data extraction methods and applied to newly-built farm. This transfer learning research is attracting further attention [28]. 
However, prediction error cannot be avoided due to wind speed uncertainty [29]. Further, quantitative characterization of the wind speed and generated power's persistence and variation is also urgently needed [30]. In view of the physical nature of the random fluctuation of wind speed and the characteristic of wind power, several studies have been carried out on their uncertainty, including instantaneous characteristics (power spectrum), short-period characteristics (daily variation), and long-period statistical characteristics.

In terms of the nature relationships of range to standard deviation of wind fluctuations, the fluctuation variance caused by turbulence is dependent on the mean wind speed per hour[31]. Literature [32] try to predict the turbulence standard deviation of wind speed. Because of the importance of long-period characteristics, the spatiotemporal complementarity between solar and wind power in the Iberian Peninsula has been researched as the key problem $[33,34]$. Additionally, wind speed variance is also an important parameter to characterize wind and turbulence intensity. Turbulence intensity can be used in fan safety design[35,36,37], life analysis[38,39,42,43], and wind farm layout design[40,41], and, hence, has long been the focus of many researchers.

Although characterization of the wind resource is important [44], the most significant one is the intermittency caused by the inherent instability of atmospheric turbulence. In [45] and [46], the measurement and analysis of intermittency for power generation and wind speed were performed based on historical data of wind speed and wind power. Although the intermittent characterization index of wind speed and power has the characteristics of daily cycle, neither the practical application of daily cycle nor the global perspective on the summarized daily modulation has been discussed.

In fact, due to the existence of the diurnal modulation of atmospheric turbulence, the diurnal periodic characteristics are reflected in the average wind speed and temperature [47, 48]. Many factors, such as atmospheric stability [49], time scale [50], near-surface temperature, turbulence intensity [51], will all influence the wind characteristics. Therefore, modeling and research on diurnal cycle characteristics are also being carried out [52,53].

In summary, the average wind speed followed by a certain law has been deeply studied presently. Scholars have studied several systematic algorithms on wind speed and its generated power prediction. However, only few studies study on turbulent wind speed due to the uncertainty caused by turbulence, and only a few researchers have conducted studies on turbulence intensity from the application aspects of wind turbines' life analysis and design of wind farm layout. Although, several researches have pointed that the average wind speed, turbulence intensity, and temperature show diurnal characteristics. There is no study that has proposed the intrinsic characteristics of spatiotemporal diurnal modulation of atmospheric turbulence from a global perspective. Furthermore, there is also absence of a systematic analysis of the influences of diurnal modulation on wind speed and wind turbine randomness, volatility, and intermittency based on the essential characterization parameters of its output power.

In this paper, the spatiotemporal diurnal modulation characteristics of atmospheric turbulence and their influence on the indeterminacy of wind speed and power generation are discussed. The rest of this paper is organized as follows: In section II, the spatiotemporal diurnal modulation characteristics of atmospheric turbulence are proposed from a global perspective based on the analysis of its physical mechanism. In section III, the influence of spatiotemporal diurnal modulation of atmospheric turbulence on wind speed and its power prodution's random fluctuation range is analyzed based on their corresponding characterization index called the variance. In section IV, the law of the influence of spatiotemporal diurnal modulation of atmospheric turbulence on the random fluctuation rate of speed is analyzed by variation index. Furthermore, this method is extended to analyze wind power fluctuation rate. In section $\mathrm{V}$, the influence of wind speed and wind power intermittency on turbulent spatiotemporal daily modulation is analyzed based on the ramp duty ratio index. Moreover, another wind power intermittency characterization parameter without daily modulation is analyzed by the start/stop frequency of the wind turbines. In section VI, considering the fluctuation range of wind speed and wind power as examples, the quantitative characterization modeling of the uncertainty and its introduction strategy in the evaluation of real-time frequency modulation capability of power grid are used to explore the feasibility of such spatiotemporal daily modulation characteristics. The seventh section is the conclusion and prospection of the paper.

\section{Intrinsic properties of spatiotemporal diurnal modulation in atmospheric turbulence}

\subsection{Diurnal modulation and spatiotemporal characteristics of atmospheric turbulence}

Atmospheric turbulence is an intrinsic factor of uncertainty in wind speed and its power output with wind turbine. Its uncertainty performance in atmospheric motion attribute to the random fluctuation of various sizes superimposed by its average wind speed and wind direction. Similarly, this also applies to the power output of wind turbines.

Turbulence is a different kind of motion that takes place in the atmospheric boundary layer (ABL). The factors affecting its formation differ during day and night with apparent diurnal periodic characteristics. Generally, the turbine hub height is in the ABL. The diurnal variation of the sun rising in the east and setting in the west highly influences the convective motion of the $\mathrm{ABL}$ in a flat terrain where surface 
roughness are uniform. Therefore, diurnal variation can reflect the change in an underlying flat surface in the boundary layer. However, the turbulence intensity in the underlying surface layer of a complex mountainous area is affected by the vortex flow around the local landform, leading to the formation of intense turbulence as well, which is stronger than that caused by sunlight, where diurnal period characteristics are submerged. Moreover, the influence of the ground is greater, when the altitude closer to the ground, leading to a greater turbulence than that at a higher altitude. The diurnal periods of flat areas, such as plains or plateaus, have common features, and the time points of maximum turbulence intensity are similar. Therefore, the diurnal period has spatiotemporal characteristics, which are derived from the intrinsic characteristics of the turbulence in ABL.

The process of controlling one parameter of a signal with another signal is defined as modulation in communication systems. Based on the influence of the diurnal period on turbulence and wind speed, this diurnal period can be considered as the modulation of wind speed. In other words, the diurnal period is a diurnal modulation process of wind speed caused by a longer weather process, and a diurnal modulation process of the atmosphere is the physical mechanism for the existence of diurnal period phenomenon in the turbulent part of wind speed and wind power. Therefore, several characterization indexes of wind speed uncertainty are affected by spatiotemporal diurnal modulation of atmospheric turbulence, such as the average wind speed of wind farm, the output power of the wind turbines, the random fluctuation part and internal intermittency, and the average temperature (heat flux) of the wind field. However, the descriptive parameters that cannot reflect the inherent characteristics of wind speed are not affected.

\subsection{Other recommendations}

The scheduling, control, and planning arrangements in a power system have different time scales. The day-ahead prescheduling planning cycle takes one day as a unit, while the real-time scheduling and optimization control takes hours as the time scale. These correspond to the $0 \sim 24 \mathrm{~h}$ day-ahead forecast of wind power and $0 \sim 4 \mathrm{~h}$ ultra-short-term forecast, respectively. Therefore, if the parameters, such as the mean time value of wind speed and wind power, wind power uncertainty and intermittency, especially for the hourly scale statistic rules, related to wind power prediction have diurnal modulation characteristics, it will have a guiding significance for the pre-dispatch before day and real-time scheduling of primary and secondary frequency modulation in the new energy power system after large-scale wind power grid connection.

Autocorrelation is a mathematical tool used to find repeated patterns and analyze value functions or sequences of signal processing, such as a periodic signal masked by noise. As for periodic sequences, the autocorrelation sequence shows periodic change [41].

\section{Influence law of turbulence diurnal modulation on wind power random fluctuation range}

\subsection{Quantitative characterization of wind power fluctuation range}

In general, based on Reynolds averaging, the actual wind speed can be divided into hourly average wind speed and turbulent wind speed. Moreover, research results show that the turbulent part of the wind speed depends on the average time strongly. Among these, a turbulence intensity model in international IEC standard realizes the wind speed fluctuation range (intensity). Later, a universal model of turbulence intensity was proposed [41], as given by equation 1 .

$$
T I=\sigma / \frac{\nu}{v}=\alpha \cdot v^{-\beta}+c
$$

Where $\sigma$ is variance of wind speed turbulence; $v$ is the mean wind speed per hour; $\alpha, \beta$, and $c$ are constants. Similarly, a model of single wind turbine/wind field power and relative variance can be established. Wind power fluctuation intensity $I_{p}$ is the characteristic parameter of power fluctuation range [42]. Here, the relative variance is the unit value of the residual fluctuation components after subtracting the mean value from the actual wind power value.

Based on the wavelet multi-scale algorithm, the multi-scale fluctuation intensity suitable for frequency modulation capability evaluation can be obtained as the minute-scale wind power fluctuation intensity $I_{p m}$ and secondary wind power fluctuation intensity $I_{p s}$, shown in equations 2 and 3 , respectively.

$$
\begin{gathered}
I_{P m}=\frac{\sigma_{m}}{\bar{P}}=\alpha_{m} \times \bar{P}^{-\beta_{m}}+c_{m} \\
I_{P_{s}}=\frac{\sigma_{s}}{\bar{P}}=\alpha_{s} \times \bar{P}^{-\beta_{s}}+c_{s}
\end{gathered}
$$

Where $\sigma_{m}$ is the instantaneous standard deviation of wind power in minute-scale; $\sigma_{s}$ is the instantaneous standard deviation of secondary wind power; $\bar{P}$ is the mean wind speed per hour; $\alpha_{m} 、 \beta_{m}$, and $c_{m}$ are the fitting constants of minute-scale wind power fluctuation intensity; $\alpha_{s}, \beta_{s}$, and $c_{s}$ are the fitting constants of secondary wind power fluctuation intensity. 


\subsection{The influence law on wind speed fluctuation range}

There are many factors that affect the actual wind speed fluctuation uncertainty, and even the three-parameter power law model has a fitting error under certain conditions, as shown in Fig. 1. The fitting error is defined as follows:

$$
e=\sigma-\left(\alpha \cdot v^{-\beta}+\mathrm{c}\right) \cdot \bar{v}
$$

where $\sigma$ is the residual fluctuation standard deviation of the actual wind speed after eliminating average.

The results are shown in Fig. 1 with autocorrelation of the fitting error. It can be seen that the fitting error has strong diurnal period characteristics. Moreover, the diurnal period change pattern is different for the four seasons.
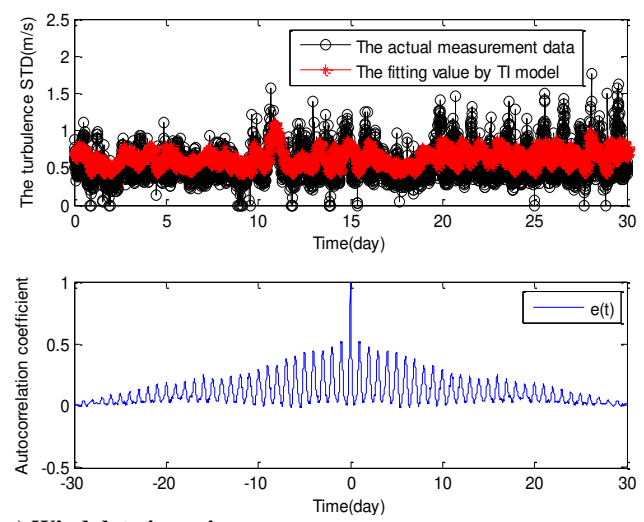

a) Wind data in spring
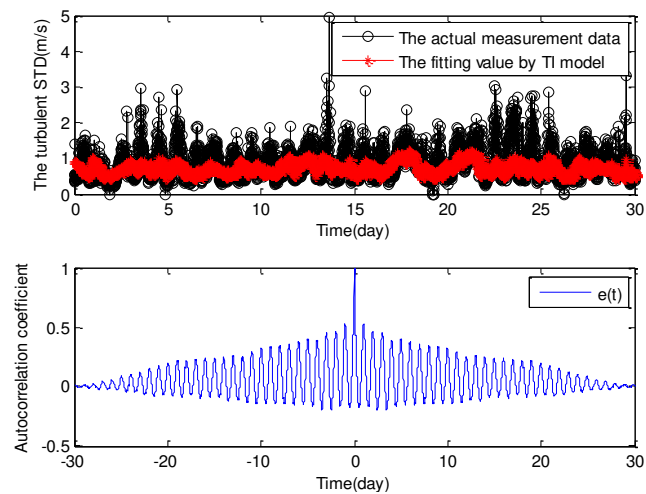

b) Wind data in summer
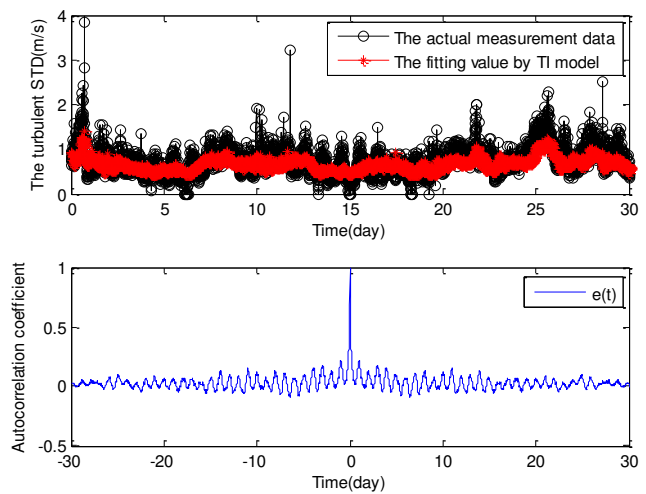

c) Wind data in autumn
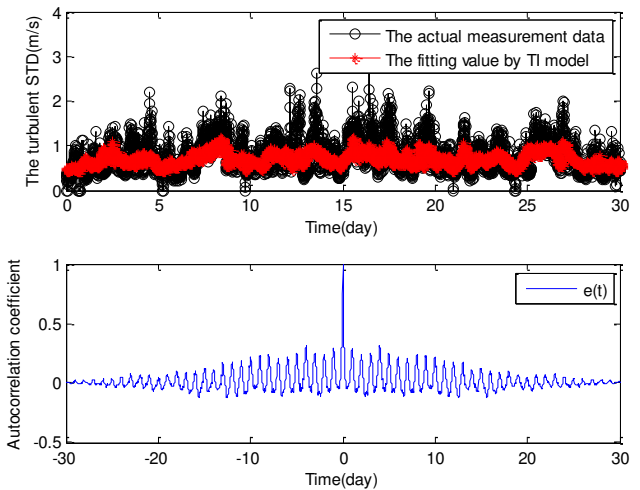

d) Wind data in winter

Fig 1. The fitting error of the model and its diurnal period pattern

Therefore, there is a diurnal periodic change pattern of turbulence intensity obviously. It indicates that the model parameters are variable throughout the day, and the differences are relatively large, which cannot be ignored.

Fig. 2 shows the variation law of the model parameters within $24 \mathrm{~h}$ obtained by fitting the data in Fig. 1 .

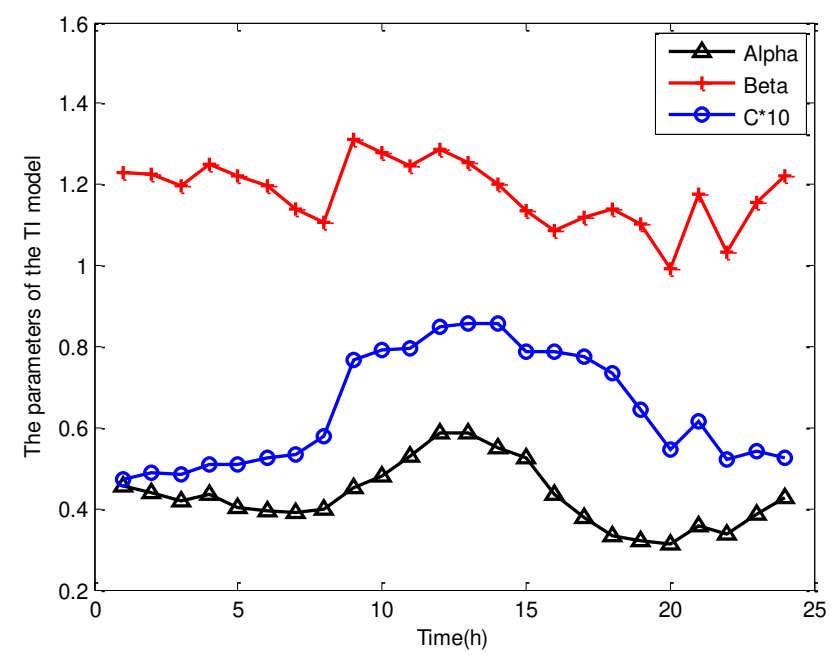

Fig 2. Model parameter variation within $24 \mathrm{~h}$

Further, from the wind turbine scheduling and controlling perspective, the average turbulence intensity is defined by the effective section in the middle of the wind speed cutting in/cutting out of the universal fan. The average turbulence intensity range from $3 \mathrm{~m} / \mathrm{s}$ to $25 \mathrm{~m} / \mathrm{s}$ in the wind speed section of the fan corresponds to the hub height of the fan, as shown in Fig. 3. The calculation used is shown in Eq. 5.

$$
\bar{I}=\frac{1}{n} \sum_{i=1}^{n} I_{i}
$$

where $I_{i}$ is the turbulence intensity corresponding to the average speed range from $3 \mathrm{~m} / \mathrm{s}$ to $25 \mathrm{~m} / \mathrm{s} ; n$ is the number of samples within the average speed range from $3 \mathrm{~m} / \mathrm{s}$ to 25 $\mathrm{m} / \mathrm{s}$. 


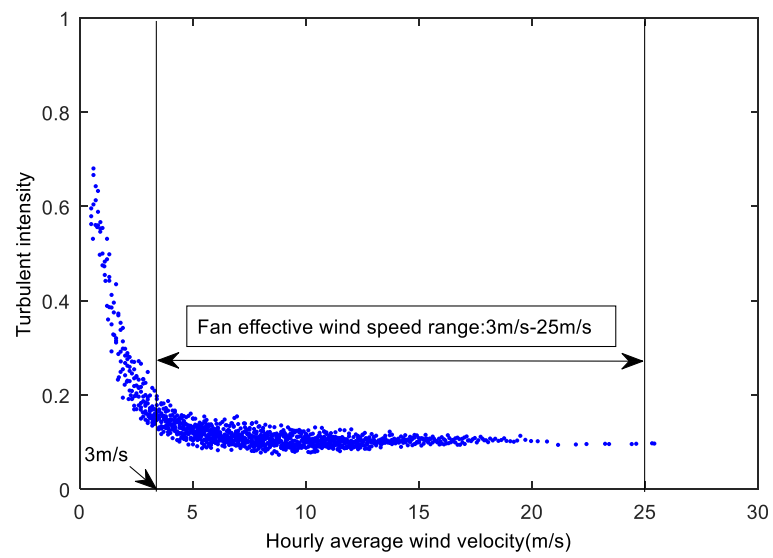

Fig 3. The hub height's average turbulence intensity

Fig. 4 shows the diurnal period variation pattern of different wind speed turbulence intensities obtained by using the fitting model. Fig. 5 shows the diurnal period patterns of different wind speed turbulence intensities obtained from the measured data. It proves the existence of the diurnal period change pattern of turbulence intensity.
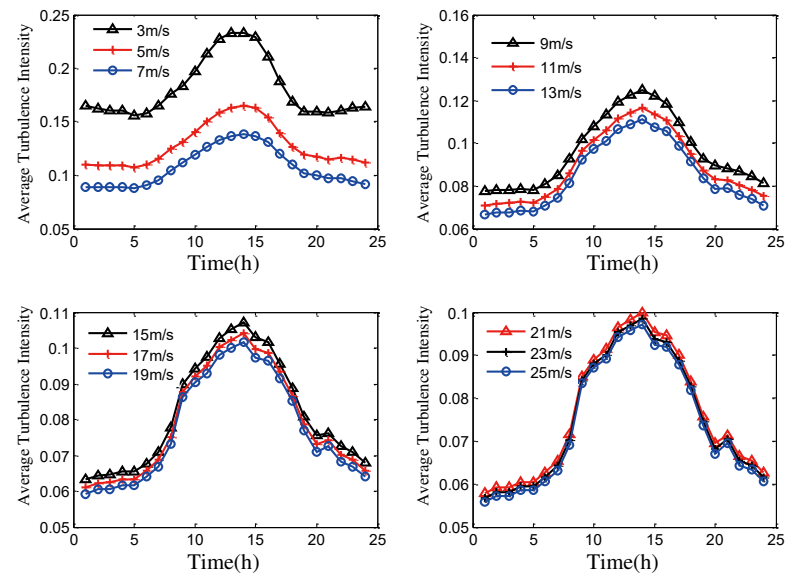

Fig 4. The variation of turbulence intensities for different wind speeds within $24 \mathrm{~h}$ using fitting model

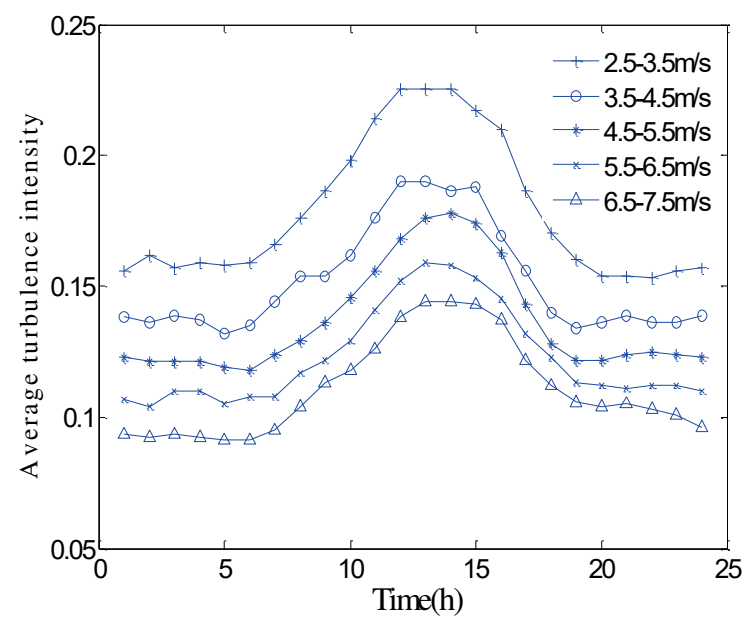

a) Wind speed range from $2.5 \mathrm{~m} / \mathrm{s}$ to $7.5 \mathrm{~m} / \mathrm{s}$

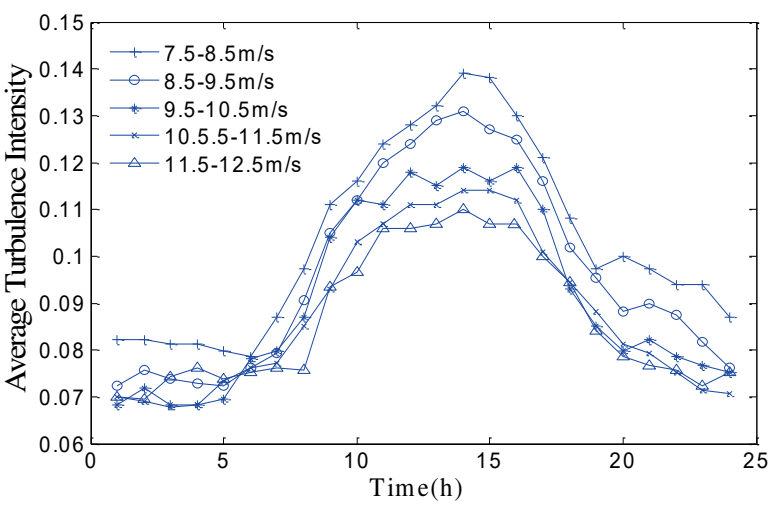

b) Wind speed range from $7.5 \mathrm{~m} / \mathrm{s}$ to $12.5 \mathrm{~m} / \mathrm{s}$

Fig 5. The variation of the mean turbulence intensities value within $24 \mathrm{~h}$ time interval (actual data)

Fig. 6 (a), (b), and (c) show seasonal and monthly variation patterns of turbulence intensity in diurnal weeks, including diurnal variation patterns of turbulence intensity in four seasons and diurnal variation patterns of turbulence intensity in twelve months. It can be seen daily cycle pattern of turbulence intensity in this region is affected by the season and month. In general, the average turbulence intensity is the highest in spring and the lowest in winter. In terms of the average turbulence intensity in a single month, the maximum value occurs in May and September. In terms of the $24 \mathrm{~h}$ variation in a day, the maximum value occurs around 14:00 15:00 in the afternoon, and the minimum value occurs around 20:00 in the evening of the same day $\sim$ 08:00 in the morning of the next day. The maximum value occurs earlier in winter compared to other seasons.

All the investigated wind farms were located in typical areas of northern China, therefore, the daily cycle patterns of the actual offshore wind farms were different. There is a diurnal cycle variation pattern of land turbulence intensity, and the driving energy is predominantly from the sun. However, the difference is mainly due to the difference in light intensity and illumination time during different seasons and months. Therefore, the diurnal modulation of atmospheric turbulence has spatiotemporal characteristics.

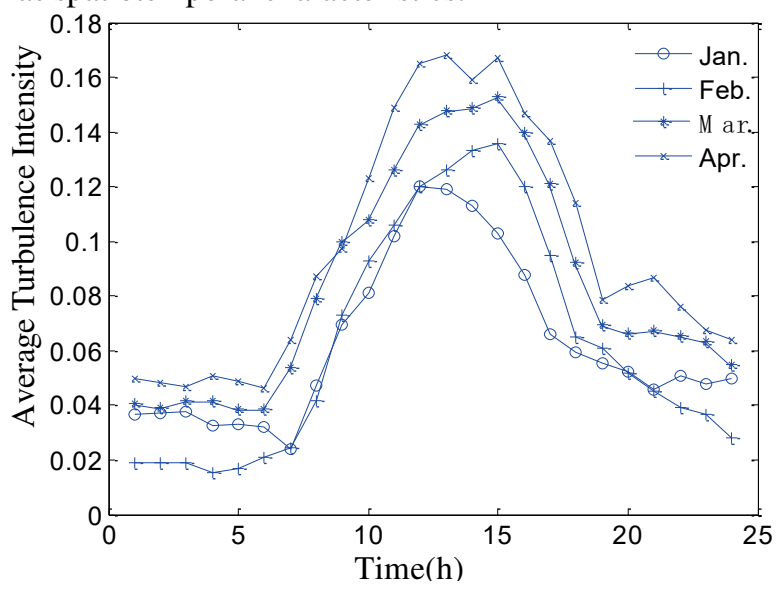

a) The diurnal cycle from January to April 


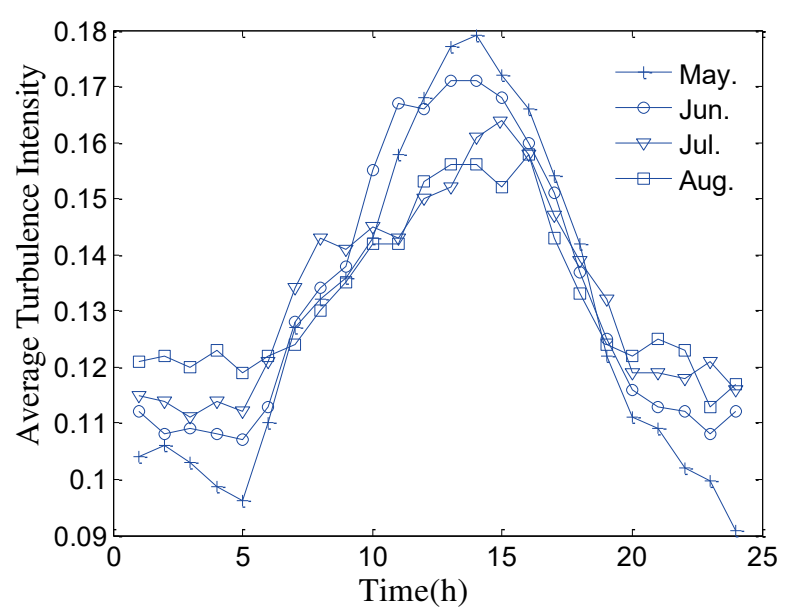

b) The diurnal cycle during May and August

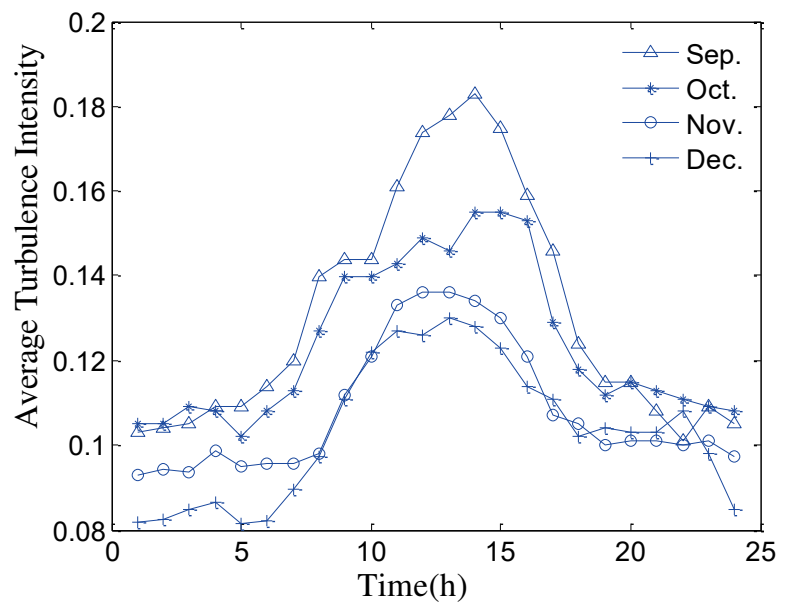

c) The diurnal cycle from September to December

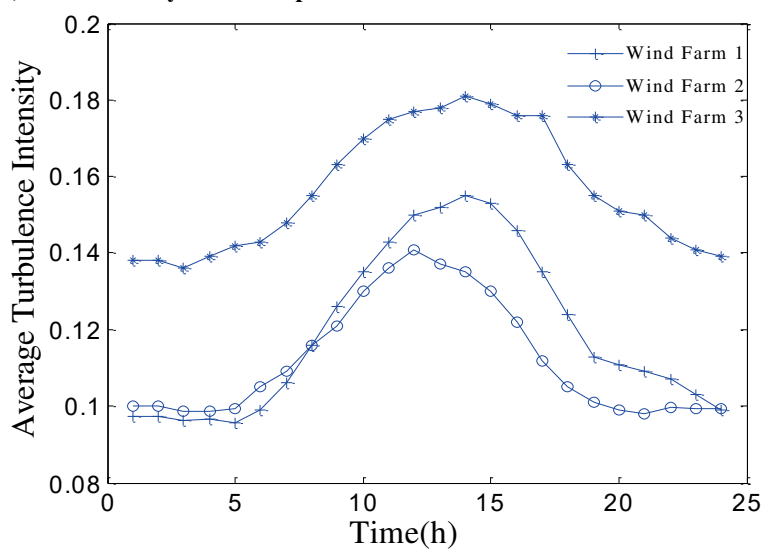

d) The diurnal cycle variation of mean TI in three different farms

Fig 6. The diurnal cycle variation of TI during different seasons and months of a year

Furthermore, the one-year data from three wind farms in different regions are analyzed based on effective average turbulence intensity parameters. Fig. 6 (d) shows the diurnal characteristics of average turbulence intensity in different regions. The diurnal cycle patterns of different wind farms differ with the time and location. The main reason for this is the difference in the latitudes and longitudes of the wind farms. Therefore, the time of sunrise and sunset is different, resulting in a time deviation of the maximum value.

As shown in Fig. 7, the influence of the sunshine on the diurnal variation is weakened by complex and diverse topography and landform, and varied surface roughness. As shown in Fig. 8, the maximum value of the average turbulence intensity corresponding to the fan at the lowest position is nearly twice that of its maximum value corresponding to the fan at the highest position. Therefore, complex topography has a great influence on the average turbulence intensity. In addition, it is greatly affected by topography and roughness at the lowest point. However, literature [41] does not elaborate on these aspects.

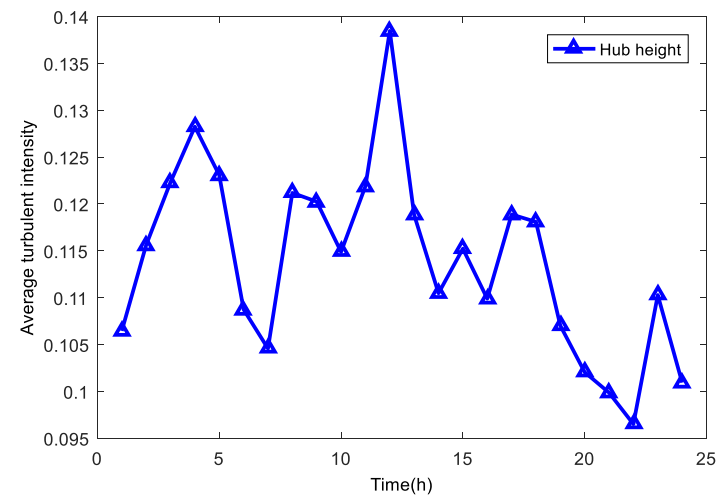

Fig 7. The diurnal cycle variation of $\mathrm{TI}$ in land farm with complex terrain

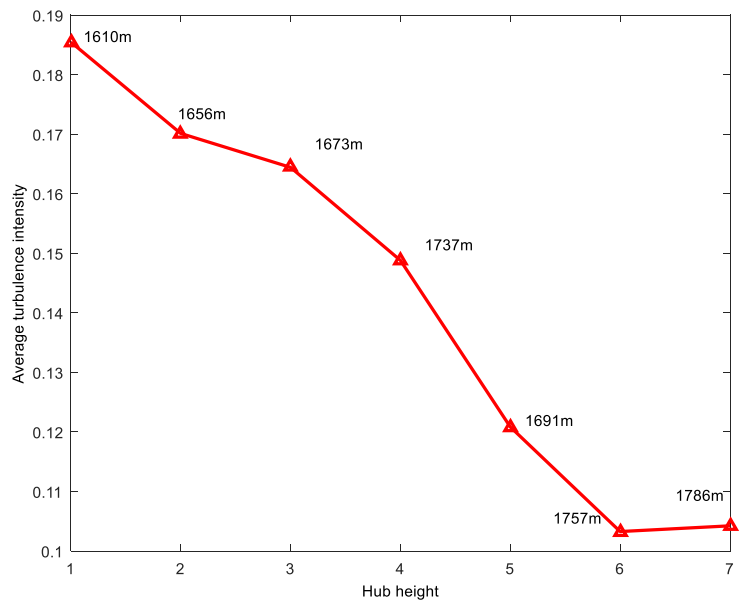

Fig 8. The diurnal cycle variation of TI in land farm with complex terrain

\subsection{The influence law of turbulence diurnal modulation on wind power fluctuation range}

The diurnal cycle characteristics of wind power fluctuation intensity are not mentioned in the existing literature. Fig. 9 shows the diurnal cycle characteristics of wind power fluctuation intensity of the different units in the same wind field. Due to the wind speed variance has diurnal cycle characteristics, the wind power variance also has diurnal cycle characteristics. Moreover, the wind power fluctuation 
intensity corresponding to different power values also has diurnal cycle characteristics. However, after the conversion of wind speed into energy by means of the fan, the regularity of the diurnal cycle change of wind power fluctuation intensity is not as apparent as that of the diurnal cycle change of wind speed turbulence intensity.

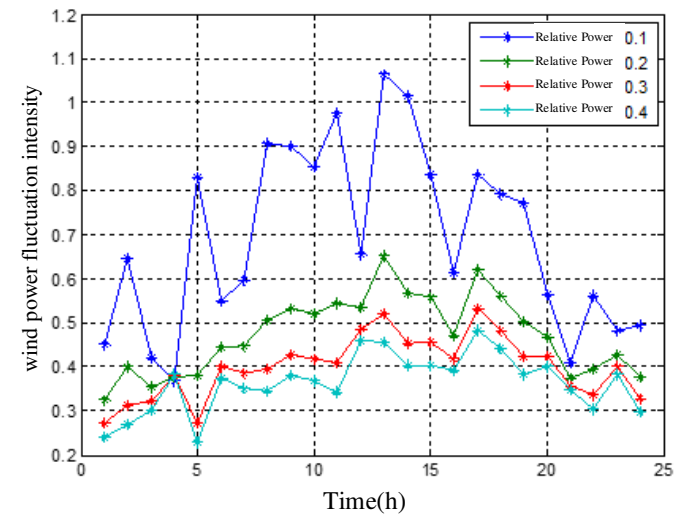

a) \#19 turbine

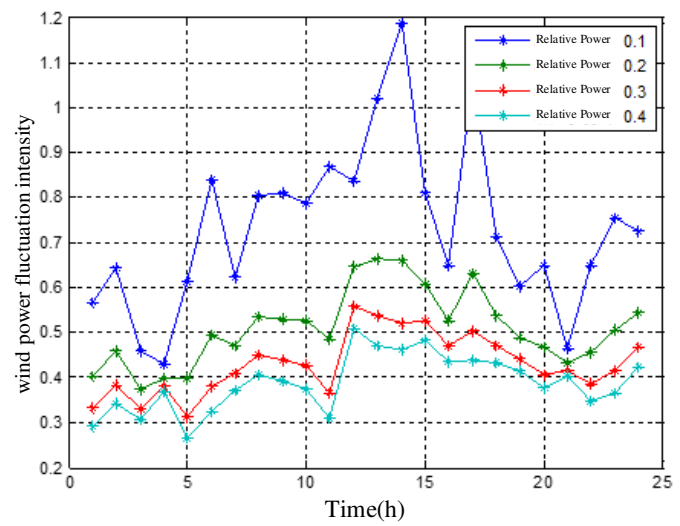

b) \#39 turbine

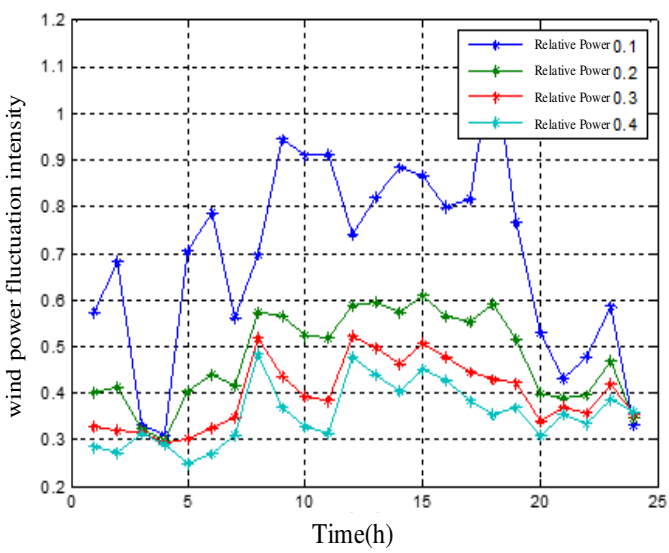

c) \#69 turbine

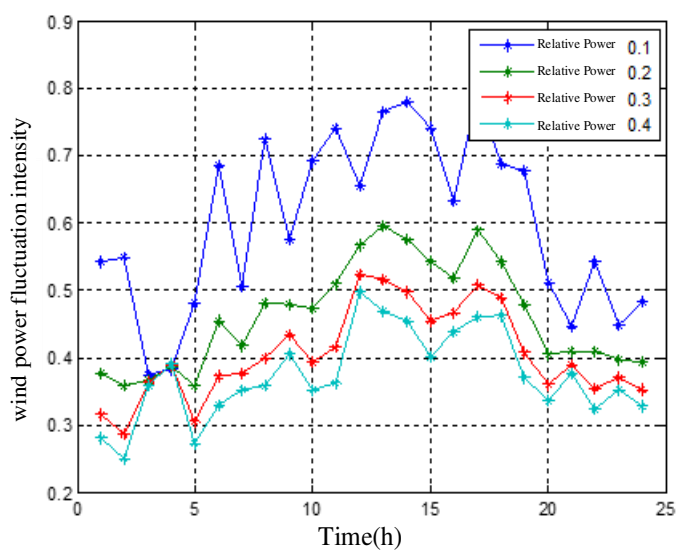

d) \#119 turbine

Fig 9. The diurnal cycle of wind power variance in same wind field

\section{Influence law of turbulence diurnal modulation on wind power random fluctuation rate}

\subsection{Quantitative characterization of wind power fluctuation rate}

In [43], variational analysis is introduced to establish a computing model of instantaneous wind speed variation based on wavelet algorithm. In addition, similar to turbulence intensity, based on the dependence of wind speed variation on hourly average wind speed, the quantitative characterization of wind speed fluctuation rate is realized. Moreover, wind power variation also has the same characteristics $\chi_{p}$ We further defined the variable intensity of wind power $\chi_{p}$ as the derived parameter to describe wind power variation quantitatively, as given by equation 6 .

$$
\chi_{p}=\frac{\left[\gamma_{p}^{*}(\Delta t)\right]^{1 / 2}}{\bar{p}^{*}}=\alpha *\left(\bar{p}^{*}\right)^{-\beta}+c
$$

where $\gamma_{p}{ }^{*}(\Delta t)$ is the relative variation of wind power; $\bar{p}^{*}$ is the unit value of the average hourly power; $\alpha, \beta$, and $c$ are fitting constants.

\subsection{Influence law of turbulence diurnal modulation on wind speed fluctuation rate}

In [43], one-month time series data was used for autocorrelation, which adopted multi-time interval variation calculation results to show that the time lag of the variation function is a periodic component in the time series with variation where the period is 1 day. In addition, the regularity of diurnal cycle change pattern remains unchanged with an increase in time interval. The diurnal cycle regularity becomes weaker only when the time interval reaches a certain level. The variation function of wind speed has the 
same diurnal cycle pattern as the variance. The time series $\gamma(\Delta t)$, as in [43], has different time lags, and the diurnal pattern of wind speed's variation function is analyzed in detail. $\gamma(\Delta t)$ is large from 8 a.m. to 6 p.m., especially at its peak between 12 noon and 4 p.m, and relatively small during other times of the day. On the basis of [43], further analysis reveal that diurnal cycle characteristics are not related to the speed, and speeds at different sizes have similar daily cycle characteristics shown in Fig. 10.

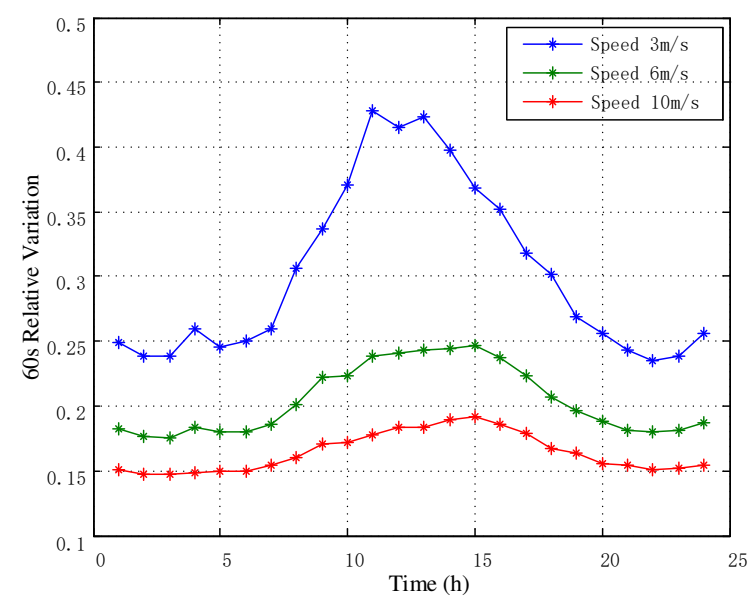

a) Wind speed: $3 \mathrm{~m} / \mathrm{s}, 6 \mathrm{~m} / \mathrm{s}, 10 \mathrm{~m} / \mathrm{s}$

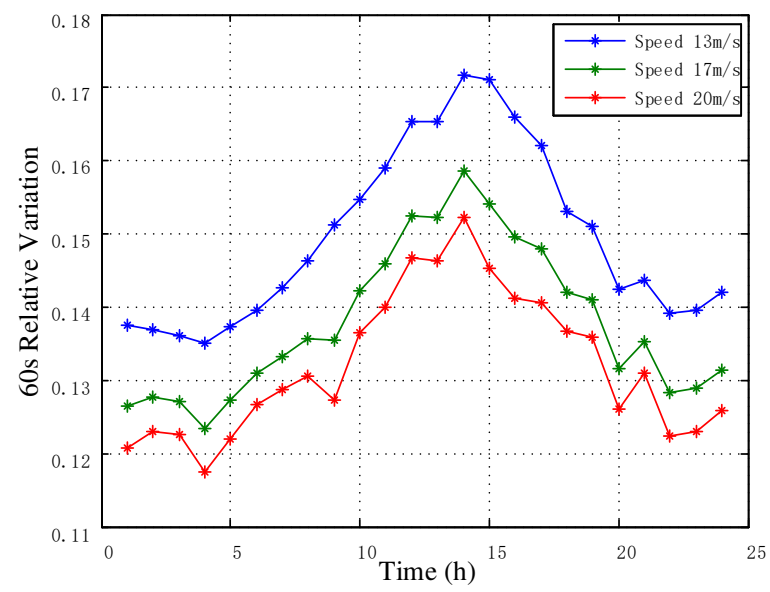

b) Wind speed: $13 \mathrm{~m} / \mathrm{s}, 17 \mathrm{~m} / \mathrm{s}, 20 \mathrm{~m} / \mathrm{s}$

Fig 10. The diurnal cycle of different wind speed variation

\subsection{The diurnal period characteristics of wind power variogram}

Based on [43], the universality of the diurnal period characteristics of wind power variogram is further analyzed. As shown in Fig. 11, the measured wind power data of multiple generating units are selected. It shows that wind power variogram is modulated by the diurnal process and has obvious diurnal period characteristics. Moreover, none of the present literature mentions the diurnal cycle characteristics of wind power variogram. Therefore, we extend the results of our research from characteristics of wind speed to its producing wind power. In power grid dispatching, the wind speed during noon has strong fluctuations at a fast rate. Therefore, when the disturbance caused by the power stroke of the power grid is suppressed, it is necessary to reasonably configure units with different suppression capacities to ensure safe and stable operation of the power grid.

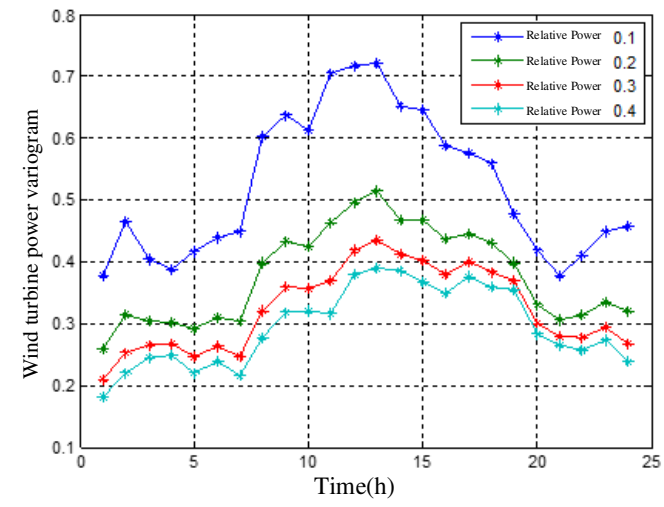

a) \#19 turbine

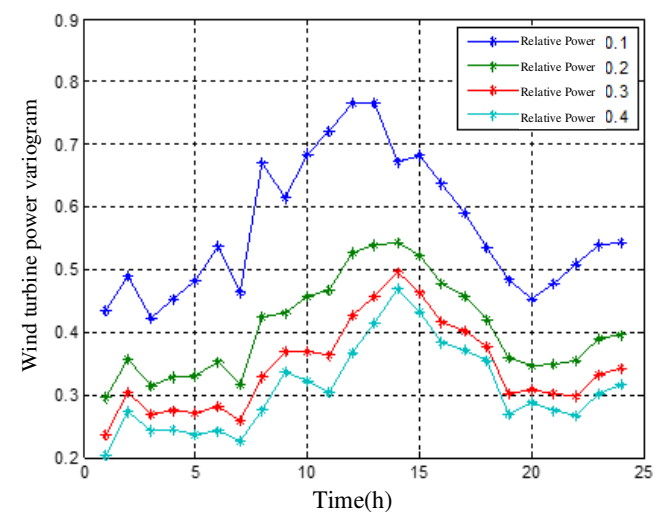

b) \#39 turbine

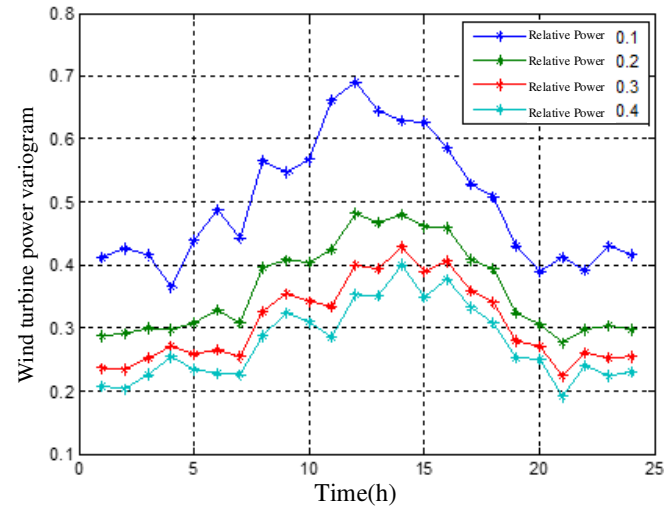

c) \#69 turbine 


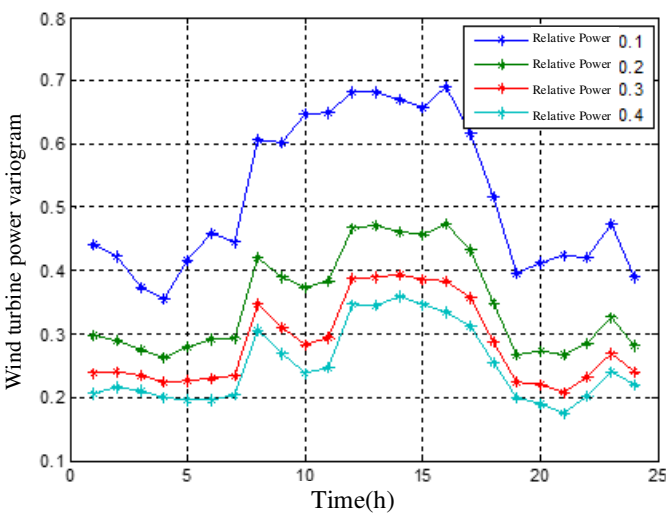

d) \#119 turbine

Fig 11. The diurnal cycle of different wind turbine power variogram in wind field

\section{Influence law of turbulence diurnal modulation on wind power intermittency}

In [45], a quantitative description method of intermittency is proposed based on the duty ratio of abrupt change in wind speed, which is defined on based of the atmospheric turbulence physical essence. Furthermore, in [46], this kind of quantitative description method is extended to wind power intermittency's definition, which is of great significance to the power system.

In [45] and [46], similar autocorrelation has been adopted to analyze the measurement parameters of wind speed and its generating power intermittently in detail. It was found that the abrupt duty cycle parameters of wind power had obvious diurnal cycle characteristics. Similar to the diurnal cycle of wind power variance and variogram parameters, the steep duty ratio between $8 \mathrm{a} . \mathrm{m}$. and $8 \mathrm{p} . \mathrm{m}$. is larger than that at other times. It reaches its daily peak between 12 noon and 4 p.m. Similar statistical analyses are performed on sufficient data from the same and different wind fields during other months. The obtained results are identical. A study on the daily-cycle characteristic of the abrupt duty cycle of wind speed at different time intervals showed that the diurnal cycle phenomenon of the abrupt duty cycle of wind speed still exists. This proves the universality of the diurnal cycle phenomenon. The sharp change in the diurnal cycle phenomenon of wind speed in duty cycle indicates that the wind power intermittency is stronger during the day than during night, Wind power intermittency reaches its daily peak between 12 noon and 4 p.m. Therefore, the intermittent characterization index reflects the intrinsic characteristics of wind power uncertainty.

In practice, several parameters are used to characterize wind power intermittency. However, the parameters that cannot describe the nature of the intermittent wind speed have no modulation effect.

\section{Applications}

\subsection{Improved wind power uncertainty model considering the diurnal modulation characteristics of atmospheric turbulence}

The study of the diurnal modulation characteristics of atmospheric turbulence on wind power uncertainty has the following practical significances for the utilization of wind power:

1) The diurnal period characteristics indicate that the affecting factors of turbulence will affect the parameters of wind power variance and variogram model. Therefore, the region, topography, seasons, and weather patterns (such as sunny and rainy weather) will have an impact on atmospheric turbulence.

2) The diurnal period of wind speed variance is a reflection of the random fluctuation of wind speed. Therefore, a given wind speed fluctuation range should be larger in places with high turbulence intensities, and vice versa, instead of a fluctuation range of equal width.

3) The wind power change rate is different at different times during a day according to the diurnal period of the wind speed variogram, which means system operators must change their strategies in different states. More specifically, when the sun is stronger, complementary power and control strategies with faster response times must be provided to ensure the safe and efficient operation of renewable energy power systems.

4 ) In addition, the diurnal cycle characteristics of wind speed variance and variogram also have certain reference value of the electricity price bidding for wind farm. In addition, the diurnal cycle characteristics of intermittency characterization indexes have a similar guiding significance for the right operation of wind farms [54].

The diurnal cycle characteristics of wind power have a great impact on the precision of qualitative model fitting. According to the fitting effect in [41] based on time-sharing modeling, we can further optimize the variation and intermittency models. Taking the variance model as an example, the model considering time-varying parameters has the higher fitting accuracy. The time-varying parameter model is shown as equation 7.

$$
\sigma(t) / \bar{v}(t)=\alpha(t) \cdot \bar{v}(t)^{-\beta(t)}+c(t)
$$

where $\sigma(t)$ is the variance of actual measurement wind speed; $\bar{v}(t)$ is the mean actual wind speed per hour; $\alpha(t)$, $\beta(t)$, and $c(t)$ are a group of constants obtained by data fitting and time-sharing modeling.

As shown in Fig. 12, the fitting error of this model considering the characteristics of diurnal cycle. Compared with Fig. 1, the results show that this model has a great fitting accuracy rather than the original one (equation 1). 

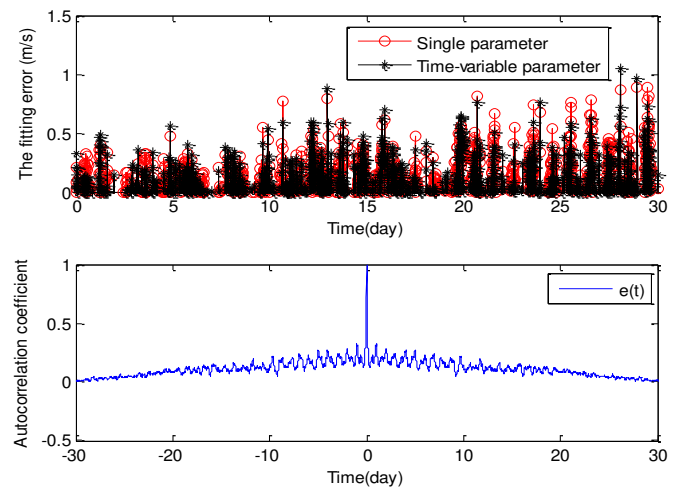

a) Wind data in spring
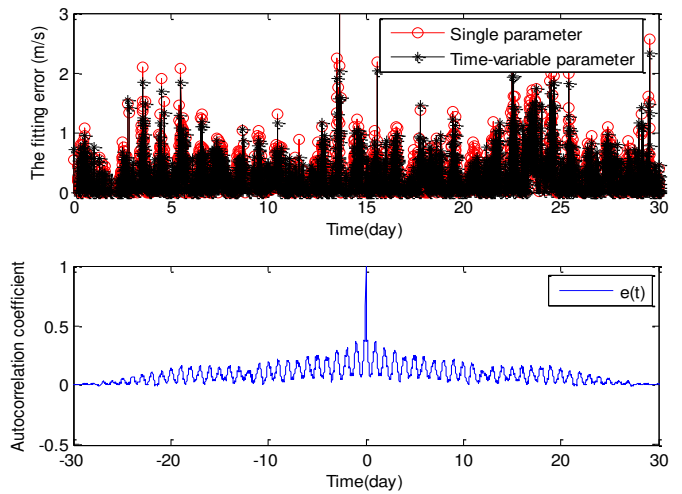

b) Wind data in summer
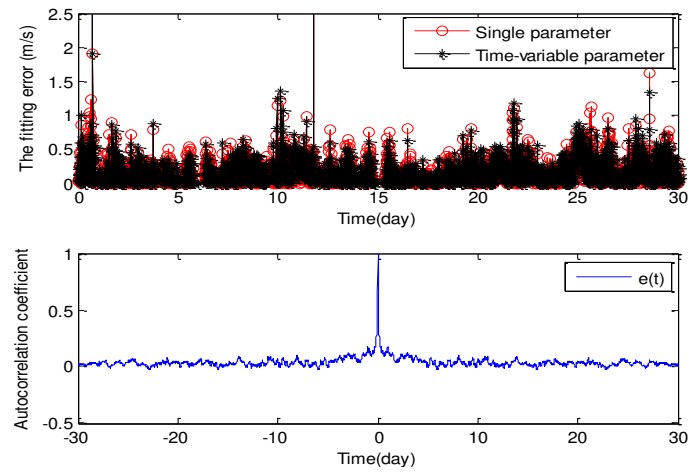

c) Wind data in autumn
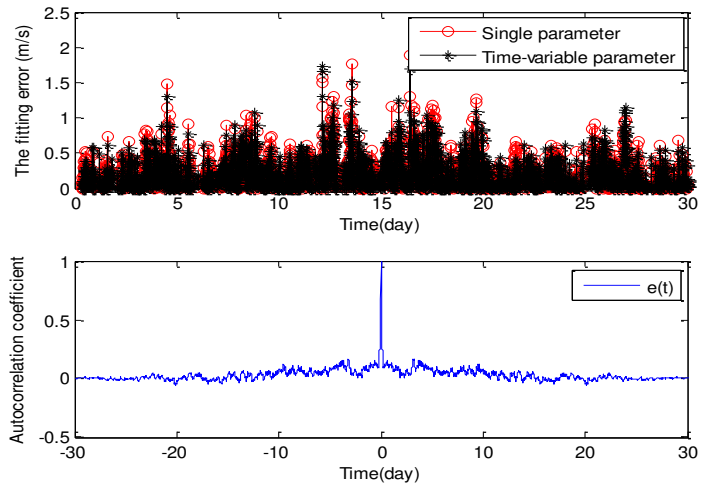

d) Wind data in winter

Fig 12. The fitting error of time variant model considering daily cycle model The following four indicators of quantitative fitting effect are statistically analyzed:

$$
\begin{aligned}
& \text { MNRE }=\frac{1}{n} \sum_{i=1}^{n}\left|\left(y_{r i}-y_{f i}\right) / y_{r i}\right| \\
& M N S E=\frac{1}{n} \sum_{i=1}^{n}\left|\left(y_{r i}-y_{f i}\right)^{2} / y_{r i}{ }^{2}\right| \\
& H A S L=k_{\left(\rho_{k}>0.6\right)} \\
& M A C=\frac{1}{n} \sum_{k=1}^{n}\left|\rho_{k}-\min \left(\rho_{k}\right)\right|
\end{aligned}
$$

where MNRE and MNSE are mean normalized relative error and mean normalized square error, respectively. $y_{r i}$ and $y_{f i}$ are the actual variance values calculated by using wind speed data and obtained by using model fitting, respectively. HASL and $M A C$ are the mean of the highly autocorrelated step size and autocorrelation coefficient, respectively. $\rho_{k}$ is the autocorrelation coefficient. $k_{\left(\rho_{k}>0.6\right)}$ is the step size corresponding to $\rho_{k}>0.6$.

It can be seen from a comparison of the results in Table I that

\begin{tabular}{|c|c|c|c|c|c|c|c|c|}
\hline \multirow{2}{*}{ Dataset } & \multicolumn{4}{|c|}{ Original model } & \multicolumn{4}{|c|}{ Time-varied model } \\
\hline & $\operatorname{MNRE}(\%)$ & $\operatorname{MNSE}(\%)$ & $H A S L$ & $M A C$ & $\operatorname{MNRE}(\%)$ & MNSE $(\%)$ & $H A S L$ & $M A C$ \\
\hline 1 & 47.53 & 13.90 & 8 & 0.1222 & 38.78 & 9.56 & 3 & 0.1091 \\
\hline 2 & 36.12 & 15.21 & 8 & 0.2661 & 28.40 & 10.44 & 2 & 0.0943 \\
\hline 3 & 27.73 & 7.68 & 2 & 0.1181 & 25.11 & 6.73 & 1 & 0.0658 \\
\hline 4 & 33.41 & 10.87 & 5 & 0.1493 & 27.71 & 7.88 & 2 & 0.0853 \\
\hline
\end{tabular}
the fitting-effect of the time-varying parameter model is better than original model.

Table 1 Statistical analysis of the fitting error

\subsection{Example analysis of frequency modulation capability estimation considering the diurnal characteristic of wind power fluctuation intensity}

According to [42], the fluctuation range measurement of wind power can be applied on the thermal power units' PFM (primary frequency modulation) and SFM (secondary frequency modulation) characteristics. The units in charge of frequency modulation can be rationally configured to meet the frequency modulation capability analysis's practical application requirements. The fluctuation intensity of minute and second wind power in a real wind farm during a day was fitted, and the corresponding fluctuation time series were calculated as follows:

1) When curve fitting is carried out at all time periods, the corresponding single-fitting parameter in equation (2) can be 
obtained. Based on the fitting model, wind power fluctuations in different time scales are estimated. The allocation scheme 1 is as follows: The proportion of primary FM unit is $80 \%$. The inequality of turbine generator unit $\delta \mathrm{iA}=0.05$. The proportion of secondary $\mathrm{FM}$ unit is $40 \%$, and the integral gain KA of secondary FM channel is 0.25 . At this time, $D_{\text {FPRA }}$ (Formula 20 in reference 42 ) of the primary frequency modulation capability of the system increases from 7.9523 to 15.9045 , and $\mathrm{D}_{\mathrm{SPR}}$ (Formula 21 in reference 42) of the secondary frequency modulation capability increases from 11.9636 to 23.9273 .

2) According to the diurnal modulation characteristics, the data are fitted during a day. Subsequently, the corresponding power law model of wind power fluctuation in this period is obtained. Based on the time-sharing wind power fluctuation power law model, the wind power fluctuation during this period can be estimated accurately. So the scheme 2 is as follows: The primary frequency control unit of share A is increased from $40 \%$ to $50 \%$., The range of turbo-generator set rate $\delta \mathrm{iA}$ is reduced from 0.05 to 0.025 . The secondary frequency modulation unit share is increased from $20 \%$ to $40 \%$. The integrator gain KA is increased from 0.25 to 0.5 . Such a system has the primary frequency control ability DFPRA increased from 7.9523 to 19.9004 , and secondary frequency modulation DSPRA increased from 11.9636 to 60.0533. The system's frequency deviation after adopting the two schemes is shown in Fig. 13. It can be seen that the standard deviation of the frequency fluctuation of the system $\sigma=0.00003416$ when scheme 1 is used in region A, thereby, being reduced to $\sigma=0.00002698$ when scheme 2 is used. Therefore, the time-sharing modeling method, considering the daily modulation characteristics, can achieve accurate estimation of wind power fluctuations, realize the optimal allocation of FM units, and provide a reference for the power grid dispatchers to rationally allocate FM units.
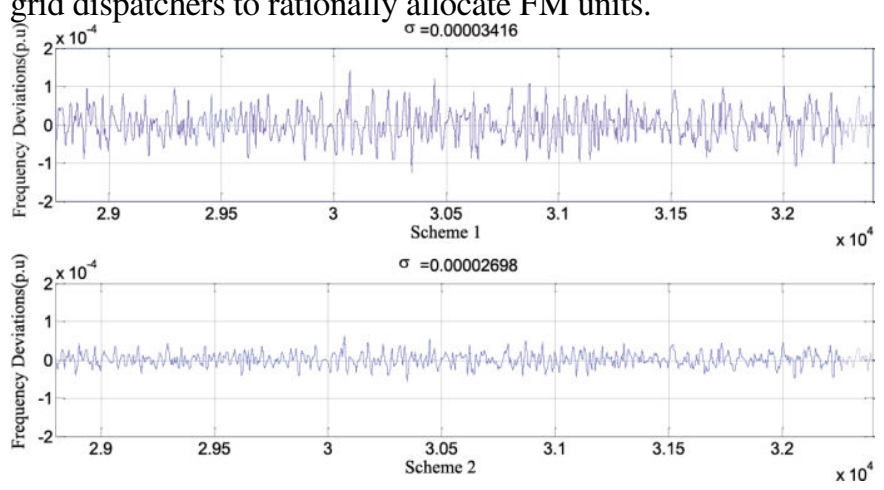

Fig 13. Comparison of simulation results of two different schemes

\section{Conclusion}

Considering the physical nature of atmospheric motion, the wind power uncertainty is studied in the present research. Based on the diurnal periodic variation model of wind power, the spatiotemporal diurnal modulation characteristics of wind speed and its power produced by atmospheric turbulence are proposed from a global perspective, and the relationship between the modulation and intrinsic characteristics of atmospheric physical motion is provided.

The diurnal cycle model of wind power fluctuation range was studied considering the intensity parameters of wind speed turbulence. On the basis of existing research, the diurnal model of wind speed and its generating power's fluctuation range and their spatiotemporal characteristics were refined and improved.

3 ) Based on the variogram function, the model of wind power fluctuation rate and its diurnal cycle model were presented. On the basis of existing research, the diurnal cycle model of wind speed and wind power fluctuation rate was refined and improved.

4 ) The existing essential characterization parameters of wind speed and wind power intermittency have diurnal cycle mode, however, there are wind power characterization indexes without diurnal cycle characteristics as well, which cannot reflect the intrinsic temperament of wind power.

5 ) Based on the existing quantitative calculation and evaluation method of power grid frequency modulation capability, which takes wind power fluctuations into account, the model fitting precision considering the diurnal cycle characteristics of wind power and its influence on the power grid frequency modulation capability evaluation are analyzed. This paper presented the spatiotemporal diurnal modulation characteristics of atmospheric turbulence from the perspective of real-time scheduling and optimal control of power systems. This is of practical significance for power grid dispatchers to adjust the frequency modulation resources in real time and ensure the safety and reliability of system frequency.

\section{Acknowledgments}

This work was funded in part the China Postdoctoral Science Foundation (Grant No. 2021T140154), the National Natural Science Foundation of China (Grant No.51877049) and CERNET Innovation Project (No. NGIICS20190801).

\section{Author contribution}

All the authors reviewed and approved the paper for submission. JW, SF, KY, KH, PE, JY have contributed to the construction of the paper framework, the typesetting and writing of the content of the paper, and the guarantee of the rigor of the content of the paper.

\section{Declarations}

Conflict of interest The authors declare that they have no conflict of interest.

Human and animal rights This article does not contain any studies with animals performed by any of the authors. 


\section{References}

[1]Sun X, Huang D, Wu G, "The current state of offshore wind energy technology development", Energy, vol. 41, no. 1, pp. 298-312, 2012.

[2]Ladenburg J. "Attitudes towards on-land and offshore wind power development in Denmark; choice of development strategy", Renewable Energy, vol. 33, no. 1, pp. 111-118, 2018.

[3]Bilgili M, Yasar A, Simsek E, "Offshore wind power development in Europe and its comparison with onshore counterpart", Renewable \& Sustainable Energy Reviews, vol. 15, no. 2, pp. 905-915, 2011,.

[4]Valentine S V, "Japanese wind energy development policy: Grand plan or group think?", Energy Policy, vol. 39, no. 11, pp. 6842-6854, 2011.

[5]Camadan E, "An assessment on the current status and future of wind energy in Turkish electricity industry", Renewable \& Sustainable Energy Reviews, vol. 15, no. 9, pp. 4994-5002, 2011.

[6]Cradden L C, "Will climate change impact on wind power development in the UK?", Climatic Change, vol. 115, no. 3-4, pp. 837-852, 2012.

[7]Juárez A A, Araújo A M, Rohatgi J S, "Development of the wind power in Brazil: Political, social and technical issues", Renewable \& Sustainable Energy Reviews, vol. 39, no. 6, pp. 828-834, 2014.

[8]Zhao Z Y, Wu P H , Xia B , et al, "Development route of the wind power industry in China", Renewable \& Sustainable Energy Reviews, vol. 34, no. 3, pp. 1-7, 2014.

[9]Shen J, Song X, Ming Z, et al, "Low-carbon development strategies for the top five power generation groups during China's 12th Five-Year Plan period", Renewable \& Sustainable Energy Reviews, vol. 34, no. 34, pp. 350-360, 2014.

[10] Baichen X , Lifeng S , Wenhua L, et al, "Study on China's wind power development path Based on the target for 2030", Renewable \& Sustainable Energy Reviews, vol. 51, pp. 197-208, 2015.

[11] Slootweg J G, Kling W L, "The impact of large scale wind power generation on power system oscillations", Electric Power Systems Research, vol. 67, no. 1, pp. 920, 2003.

[12] Makarov Y V, Loutan C, Ma J, “Operational impacts of wind generation on California power systems", IEEE Transactions on Power System, vol. 24, no. 2, pp. 1039-1050, 2009.

[13] Callegari G, Capurso P, Lanzi F, et al, "Wind power generation impact on the frequency regulation: Study on a national scale power system", Wind Energy, pp. 1-6, 2010.

[14] Ren G, Liu J, Wan J, et al, “Overview of wind power intermittency: Impacts, measurements, and mitigation solutions" Applied Energy, vol. 204, pp. 47-65, 2017.

[15] Wu J, Wang Z X, Wang G Q, "The key technologies and development of offshore wind farm in China"
Renewable and Sustainable Energy Reviews, vol. 34, pp. 453-462, 2014.

[16] He Y , Pang Y, Zhang J , et al, "Feed-in tariff mechanisms for large-scale wind power in China", Renewable and Sustainable Energy Reviews, vol. 51, pp. 9-17, 2015.

[17] Wang, Wei, et al, "Feasibility analysis of changing turbine load in power plants using continuous condenser pressure adjustment", Energy, vol. 64, pp. 533-540, 2014.

[18] Wang, Wei, et al, "Combined heat and power control considering thermal inertia of district heating network for flexible electric power regulation." Energy, vol. 169, pp. 988-999, 2019.

[19] Howlader A M, Urasaki N, Yona A, et al, "A review of output power smoothing methods for wind energy conversion systems" Renewable \& Sustainable Energy Reviews, vol. 26, no. 10, pp. 135-146, 2013.

[20] Mahela O P , Shaik A G , Kazmerski L, "Comprehensive overview of grid interfaced wind energy generation systems", Renewable \& Sustainable Energy Reviews, vol. 57, pp. 260-281, 2016.

[21] Wang J, Song Y, Feng L, et al, "Analysis and application of forecasting models in wind power integration: A review of multi-step-ahead wind speed forecasting models", Renewable \& Sustainable Energy Reviews, vol. 60, pp. 960-981, 2016.

[22] Ssekulima E B, Anwar M B, Hinai A A, et al, "Wind speed and solar irradiance forecasting techniques for enhanced renewable energy integration with the grid: a review", Iet Renewable Power Generation, vol. 10, no. 7, pp. 885-989, 2016.

[23] Al-Yahyai S, Charabi Y, Gastli A, "Review of the use of Numerical Weather Prediction (NWP) Models for wind energy assessment", Renewable \& Sustainable Energy Reviews, vol. 14, no. 9, pp. 3192-3198, 2010.

[24] Yao Z, Wang J, Wang X, "Review on probabilistic forecasting of wind power generation", Renewable \& Sustainable Energy Reviews, vol. 32, no. 5, pp. 255270, 2014.

[25] Shi J, Guo J, Zheng S, "Evaluation of hybrid forecasting approaches for wind speed and power generation time series", Renewable \& Sustainable Energy Reviews, vol. 16, no. 5, pp. 3471-3480, 2012.

[26] Lecun Y, Bengio Y, Hinton G, "Deep learning", Nature, vol. 521, no. 7553, pp. 436,2015.

[27] Wan J , Liu J , Ren G , et al. "Day-Ahead Prediction of Wind Speed with Deep Feature Learning", International Journal of Pattern Recognition and Artificial Intelligence, vol. 30, no. 05, pp.1-20, 2016.

[28] Hu Q, Zhang R, Zhou Y. "Transfer learning for shortterm wind speed prediction with deep neural networks", Renewable Energy, vol. 85, pp. 83-95, 2016.

[29] Bludszuweit H, Domínguez-Navarro J A, Llombart A, "Statistical analysis of wind power forecast error", IEEE Transactions on Power Systems, vol. 23, no. 3, pp. 983-991, 2008. 
[30] Li J H, Li J M, Wen J Y, et al, "Generating wind power time series based on its persistence and variation characteristics", Science China Technological Sciences, vol. 57, no. 12, pp. 2475-2486, 2014.

[31] Markee E H. On the relationships of range to standard deviation of wind fluctuations, "Monthly Weather Review", vol. 91, no. 2, pp. 83-87, 1963.

[32] Ren G, Liu J, Wan J, et al. "Prediction of the Wind Speed Turbulence Standard Deviation". Journal of Environmental Informatics. vol.32, no.1, pp. 1-13, 2018.

[33] Hill D C, Mcmillan D, Bell $\mathrm{K} R \mathrm{~W}$, et al, "Application of Auto-Regressive Models to U.K. Wind Speed Data for Power System Impact Studies", IEEE Transactions on Sustainable Energy, vol. 3, no. 1, pp. 134-141, 2011.

[34] Jerez S, Trigo R M, Sarsa A, et al, "Spatio-temporal Complementarity between Solar and Wind Power in the Iberian Peninsula", Energy Procedia, vol. 40, pp. 48-57, 2013.

[35] Barthelmie R J, Frandsen S T, Nielsen M N, et al, "Modelling and measurements of power losses and turbulence intensity in wind turbine wakes at Middelgrunden offshore wind farm", Wind Energy, vol. 10, no. 6, pp. 517-528, 2010.

[36] Früh W G, Creech A C W, Maguire A E, "Turbulence Characteristics in Offshore Wind Farms from LES Simulations of Lillgrund Wind Farm", Energy Procedia, vol. 59, pp. 182-189, 2014.

[37] Gualtieri G, "Surface turbulence intensity as a predictor of extrapolated wind resource to the turbine hub height", Renewable Energy, vol. 78, pp. 68-81, 2015.

[38] Geng X, Zhou L, Freedman J M, et al, "A case study of effects of atmospheric boundary layer turbulence, wind speed, and stability on wind farm induced temperature changes using observations from a field campaign", Climate Dynamics, vol. 46, no. 7-8, pp. 2179-2196, 2016.

[39] Bardal L M, STran L R, "Influence of turbulence intensity on wind turbine power curves", Energy Procedia, vol. 137, pp. 553-558, 2017.

[40] Cheynet E, Jakobsen J B, Obhrai C, "Spectral characteristics of surface-layer turbulence in the North Sea”, Energy Procedia, vol. 137, pp. 414-427, 2017.

[41] Ren G, Liu J, Wan J, et al, "The analysis of turbulence intensity based on wind speed data in onshore wind farms", Renewable Energy, 123, pp. 756766, 2018.

[42] Guo Y, Wang Q, Zhang D, et al, "A stochasticprocess-based method for assessing frequency regulation ability of power systems with wind power fluctuations", Journal of Environmental Informatics, vol.32, no.1, pp. 45-54, 2018.

[43] Liu J, Ren G, Wan J, et al, "Variogram time-series analysis of wind speed", Renewable Energy, vol. 99, pp. 483-491, 2016.
[44] Cosseron A , Gunturu U B , Schlosser C A, "Characterization of the Wind Power Resource in Europe and its Intermittency", Energy Procedia, vol. 40, pp. 58-66, 2013.

[45] Ren G, Liu J, Wan J, et al, "Measurement and statistical analysis of wind speed intermittency", Energy, vol. 118, pp. 632-648, 2016.

[46] Ren G, Wan J, Liu J, et al, "Analysis of wind power intermittency based on historical wind power data", Energy, vol. 150, pp. 482-492.

[47] Qu M, Wan J, Hao X, "Analysis of diurnal air temperature range change in the continental United States", Weather \& Climate Extremes, vol. 4, pp. 86-95, 2014.

[48] Chien H, Cheng H Y, Yang K H, et al, "Diurnal and semidiurnal variability of coastal wind over Taiwanese waters", Wind Energy, vol. 18, no. 8, pp. 1353-1370, 2015.

[49] Wharton S, Lundquist J K. "Assessing atmospheric stability and the impacts on wind characteristics at an onshore wind farm". Lawrence Livermore National Lab.(LLNL), Livermore, CA (United States), 2010.

[50] Chien H, Cheng H, Yang K, et al, "Diurnal and semidiurnal variability of coastal wind over Taiwanese waters", Wind Energy, vol. 18, no. 8, pp. 1353-1370, 2015.

[51] Smith C M, Barthelmie R J, Pryor S C. "In situ observations of the influence of a large onshore wind farm on near-surface temperature, turbulence intensity and wind speed profiles". Environmental Research Letters, vol. 8, no. 3, pp.034006, 2013.

[52] Akinnubi R T, Adeniyi M O, "Modeling of diurnal pattern of air temperature in a tropical environment: IleIfe and Ibadan, Nigeria", Modeling Earth Systems \& Environment, no. 2, pp. 1-19, 2018.

[53] Kanamori H, Yasunari T, Kuraji K, "Modulation of the Diurnal Cycle of Rainfall Associated with the MJO Observed by a Dense Hourly Rain Gauge Network at Sarawak, Borneo", Journal of Climate, vol. 26, no. 13, pp. 4858-4875, 2013.

[54] Li C, Peng H, Sun J, "Predictive control and sizing of energy storage to mitigate wind power intermittency", Wind Energy, vol. 19, no. 3, pp. 437-451, 2016. 